\title{
Experimental Study on Two-phase Adiabatic Expansion in a Reciprocating Expander with Intake
} and Exhaust Processes

\author{
Hiroshi Kanno*and Naoki Shikazono** \\ *Railway Technical Research Institute, 2-8-38 Hikari-cho Kokubunji-shi, Tokyo, Japan \\ ** The University of Tokyo, 4-6-1 Komaba Meguro-ku, Tokyo, Japan
}

\begin{abstract}
In the present study, visualization and measurement of two-phase adiabatic expansion in a reciprocating cylinder with intake and exhaust processes is carried out. Experimental setup with piston and cylinder which mimics reciprocating expander was constructed and boiling phenomenon is visualized. Working fluids are water and ethanol, and their inlet temperatures are 100 and $80{ }^{\circ} \mathrm{C}$, respectively. The piston and cylinder are made of polycarbonate with diameter of $D_{\mathrm{p}}=55 \mathrm{~mm}$. The inner pressure is measured by the pressure sensor embedded in the piston. Indicated work and indicated adiabatic efficiency are calculated from the $P-V$ diagram. The effects of heat capacity loss from the working fluid to the inner wall and the remained liquid, injection loss and non-equilibrium loss are evaluated. Evaporated gas velocity at the interface is calculated from the volume and density of the vapor phase, which is found to be almost proportional to the piston velocity. The adiabatic efficiency increases with the piston velocity due to the reduction of heat capacity loss. When the maximum piston velocity exceeds $300 \mathrm{~mm} / \mathrm{s}$, the effect of heat capacity loss becomes negligible. Measured indicated adiabatic efficiency of water is about $86 \%$ at maximum piston velocity of $v_{\mathrm{p}, \max }=380 \mathrm{~mm} / \mathrm{s}$, while that of ethanol is about $82 \%$ for the same condition.
\end{abstract}

Keywords: Two-phase flow, Expander, Adiabatic efficiency, Boiling, Steam cycle

\section{Introduction}

In recent years, waste heat recovery systems from moderate to low temperature heat sources such as organic Rankine cycles (ORCs) are attracting large attentions and have been widely investigated in order to improve the energy utilization efficiency. Among them, trilateral cycle has a potential of achieving high exergy recovery efficiency [1-5]. In the trilateral cycle, working fluid is pressurized and kept as a single liquid phase during the heating process. Heat is transferred from the heat source to the single phase working fluid, which results in low exergy loss during the heat exchange process due to excellent temperature profile matching. Therefore, exergy efficiency of the trilateral cycle can be theoretically the highest among other heat cycles when the heat source temperature descends during the heat exchange process. On the other hand, in the expansion process of the trilateral cycle, working fluid is introduced as a liquid and then flashed to liquid-vapor two-phase. This two-phase expander is one of the key components to realize the trilateral cycle system. 
For two-phase expansion or wet-vapor expansion, the volumetric expander is preferable from the viewpoint of erosion durability. There are several studies on wet-vapor expansion for Lysholm turbine expander. Smith et al. [6-8] estimated the performance and cost of trilateral flash cycle using Lysholm twin screw turbine. They reported that the adiabatic efficiency of the expander can reach $70 \%$, and that the trilateral flash cycle can produce 1.8 times larger output power than the simple Rankine cycle from hot steam of 100-200 ${ }^{\circ} \mathrm{C}$. Ohman et al. [9] investigated Lysholm turbine and reported that peak efficiency is sensitive to the inlet vapor condition, and that further investigation for the inlet two phase condition is needed. Oreijah et al. [10] conducted an experimental study to compare trilateral flash cycle and ORC using screw expanders. They reported that the trilateral cycle shows a larger power generation than conventional ORCs, but the expander can be operated at lower rotational speed in the ORCs than in the trilateral cycle.

When using the heat source of moderate temperature, the expansion ratio becomes very large in the expansion process of the trilateral cycle [1-2]. To overcome this difficulty, a reciprocating expander should be a preferable choice since it can be designed for large expansion ratio conditions. Steffen et al. [11] proposed a novel trilateral cycle using cyclone separation and reciprocating expander, and simulated the influence of injection timing, material of cyclone, the size and frequency of the reciprocating expander. They concluded that effective thermal insulation of the cyclone wall is important, and found that large stroke volume and engine speed decrease the isentropic efficiency of the expander due to the influence of injection timing. They also reported that the cycle using water as a working fluid has 1.35 to 1.7 times higher exergy efficiency than the ORCs ever studied. Bao et al. [12] reviewed the working fluids and capacities, costs and advantages of different expander types, and reported that reciprocating piston expander has wide adaptability for variable working conditions and tolerance for two-phase expansion.

A two-phase expansion in adiabatic condition is called as flash evaporation. Flash evaporation phenomenon has been studied in the field of refrigeration, desalination, nuclear reactor, jet nozzle or other chemical processes. Yan et al. [14] and Zhang et al. [15] carried out experiments on static and circulatory flash evaporation and investigated the steam-carrying effect. Saury et al. [16] studied flash evaporation of water film and proposed a correlation between the dimensionless maximum mass flow rate, dimensionless initial temperature, depressurization rate, superheat and initial water height. Mutair et al. [17] conducted an experimental study on flash evaporation from a superheated water jet. They concluded that the inflection point and evaporation end heights can be normalized with the nozzle diameter, and can be correlated with Weber, Froude and Jacob numbers.

The above flash evaporation studies were carried out in a flash chamber, but did not focus on the output work which could be taken out from the system. Therefore, further investigations on two-phase adiabatic expansion to increase output power and to improve adiabatic efficiency are needed. In the actual reciprocating expander, expansion process is divided into three major processes, i.e. intake, expansion and exhaust. In the intake process, hot working fluid is introduced into the cold cylinder which is cooled during the preceding expansion cycle. If the cold liquid remains after the exhaust process, this may also cool the hot inlet liquid. Such heat capacity loss deteriorates adiabatic efficiency. On the other hand, remained bubbles may effectively induce initial phase change. Therefore, two-phase expansion experiments including intake and exhaust processes should be conducted, and the effects such as heat capacity loss and initiation of phase change should be evaluated.

In the present study, working fluid is expanded in a thermally insulated cylinder to investigate the basic characteristics of two-phase adiabatic expansion in a reciprocating expander with intake, expansion and exhaust processes. Boiling phenomenon is visualized by the high speed micro scope. The working fluid and the setup are warmed up before the expansion experiment to exclude the effect of heat dissipation loss to the atmosphere. A pressure 
sensor and a thermo-couple are embedded in the piston to measure vapor pressure and temperature inside the cylinder. The indicated output power and adiabatic efficiency are obtained from the measured $P-V$ diagram. The effects of three loss mechanisms, i.e. heat capacity loss, non-equilibrium loss and injection loss are evaluated. 


\begin{tabular}{|c|c|}
\hline \multicolumn{2}{|c|}{ NOMENCLATURE } \\
\hline$c_{\mathrm{p}}$ & Liquid heat capacity $[\mathrm{kJ} /(\mathrm{kg} \cdot \mathrm{K})]$ \\
\hline$D$ & Diameter $[\mathrm{mm}]$ \\
\hline E & Energy $[\mathrm{kJ}]$ \\
\hline$g$ & Gravity acceleration $\left[\mathrm{m} / \mathrm{s}^{2}\right]$ \\
\hline$h$ & Heat transfer coefficient $\left[\mathrm{W} /\left(\mathrm{m}^{2} \cdot \mathrm{K}\right)\right)$ \\
\hline$l_{v}$ & Latent heat $[\mathrm{kJ} / \mathrm{kg}]$ \\
\hline$m$ & Mass $[\mathrm{kg}]$ \\
\hline$p$ & Pressure $[\mathrm{MPa}]$ \\
\hline$Q$ & Heat $[\mathrm{kJ}]$ \\
\hline$t$ & Time $[\mathrm{s}]$ \\
\hline$S$ & Interface area $\left[\mathrm{m}^{2}\right]$ \\
\hline$T$ & Temperature $\left[{ }^{\circ} \mathrm{C}, \mathrm{K}\right]$ \\
\hline$u$ & Specific internal energy $[\mathrm{kJ} / \mathrm{kg}]$ \\
\hline$v$ & Velocity $[\mathrm{mm} / \mathrm{s}]$ \\
\hline$V$ & Volume $\left[\mathrm{m}^{3}\right]$ \\
\hline$W$ & Work $[\mathrm{kJ}]$ \\
\hline$z$ & Piston displacement [mm] \\
\hline \multicolumn{2}{|c|}{ Greek symbols } \\
\hline$\alpha$ & Acceleration $\left[\mathrm{mm} / \mathrm{s}^{2}\right]$ \\
\hline$\varepsilon$ & Ratio \\
\hline$\Delta$ & Difference \\
\hline$\lambda$ & Thermal conductivity $[\mathrm{W} /(\mathrm{m} \cdot \mathrm{K})]$ \\
\hline$\mu$ & Viscosity $[\mathrm{Pa} \cdot \mathrm{s}]$ \\
\hline$\rho$ & Density $\left[\mathrm{kg} / \mathrm{m}^{3}\right]$ \\
\hline$\sigma$ & Surface tension $[\mathrm{mN} / \mathrm{m}]$ \\
\hline$\eta$ & Efficiency [\%] \\
\hline$\zeta$ & Loss ratio $[\%]$ \\
\hline \multicolumn{2}{|c|}{ Subscripts } \\
\hline 0 & Initial condition \\
\hline $\mathrm{ad}$ & Adiabatic \\
\hline ave & Average \\
\hline b & Bubble \\
\hline cut & Cut-off \\
\hline cyl & Cylinder \\
\hline $\exp$ & Expansion \\
\hline $\mathrm{fl}$ & Working fluid \\
\hline he & Heat capacity \\
\hline inj & Injection \\
\hline inter & Interface \\
\hline ise & Isentropic (quasi-static) \\
\hline liq & Liquid \\
\hline loss & Loss \\
\hline $\max$ & Maximum \\
\hline NE & Non-equilibrium \\
\hline $\mathrm{p}$ & Piston \\
\hline sat & Saturate \\
\hline sus & Bottom stainless plate \\
\hline vap & Vapor \\
\hline vol & Volume \\
\hline - & Difference \\
\hline \multicolumn{2}{|c|}{ Superscripts } \\
\hline
\end{tabular}




\section{Experimental setup and procedure}

\subsection{Experimental setup}

Figure 1 shows the schematic of the experimental setup. The cylinder is a double pipe made of polycarbonate. The piston with diameter of $D_{\mathrm{p}}=55 \mathrm{~mm}$ is also made of polycarbonate. The bottom of the cylinder is made of thin stainless plate with thickness of $0.8 \mathrm{~mm}$. Mechanisms to introduce hot working fluid into the cylinder and to exhaust cold two phase flow are added to the original setup for the two-phase experiment in the previous study [18]. Water and ethanol are used as the working fluids, and their inlet temperatures are $100{ }^{\circ} \mathrm{C}$ and $80{ }^{\circ} \mathrm{C}$, respectively. Working fluid in supply-tank No.1, pre-heater No.2, and heater No.4 are heated to the operating temperature $T_{0}$.

Before starting the expansion experiment, hot air from the heater No. 8 is introduced to the double pipe in order to heat the pipe wall. The temperature of hot air is controlled by the heat regulator and the solid state relay. Inner wall temperature is measured by the thermo-couple. When the wall temperature reaches desired operating temperature, hot air supply is stopped by switching the valve No. 13. Then, the cross valve No.14 is switched immediately and remained hot air is withdrawn to the vacuum pump to ensure vacuum insulation. We carried out the calibration experiment to evaluate the performance of vacuum insulation. Figure 2 shows the water vapor temperature change from $T_{\text {inj }}=100{ }^{\circ}$ Cinside the vacuum insulated cylinder. The piston is stopped after the injection process. The temperature change is about $0.2{ }^{\circ} \mathrm{C} / \mathrm{sec}$.

At the beginning of the expansion process, the heated working fluid is introduced by the plunger No. 3 pushed by the actuator No.11. The working fluid introduced into the cylinder No.5 is expanded by the piston pulled by the actuator No.10. At the beginning of exhaust process, the exhaust valve is opened by DC solenoid and the working fluid in the cylinder is exhausted to the vacuum tank No.6. The back pressure of the vacuum tank is kept at $0.02 \mathrm{MPa}$.

Figure 3 shows the movements of the piston and the plunger. The piston and the plunger are controlled to obtain desired amount and timing of the liquid injection. In order to reproduce the movement of reciprocating expander, the piston is accelerated and decelerated by constant acceleration $\alpha_{\mathrm{p}}$. Figure 3 (b) shows the point of cut-off where the injection of the working fluid to the cylinder is completed. The cut-off timing which is the timing to stop introducing the working fluid is determined by the maximum plunger displacement $v_{\mathrm{pl} \text {, max }}$, as shown in Fig. 2 (b). The cut-off volume ratio $\varepsilon_{\text {cut,vol }}$ is defined by Eq. (1), and the expansion ratio $\varepsilon_{\text {exp }}$ is defined by Eq. (2). Table 1 shows the experimental condition. The maximum piston velocity is varied from $v_{\mathrm{p}, \max }=42.4$ to $371.6 \mathrm{~mm} / \mathrm{s}$.

In this experiment, the inner pressure is measured by the pressure sensor embedded in the piston. The vapor phase temperature is measured by sheath type thermocouple with outer diameter of $0.3 \mathrm{~mm}$. The measured vapor temperature and pressure satisfied the saturation condition, so the gas phase is considered to be saturated. In addition, since the gas dynamic pressure is much smaller than the absolute pressure, gas phase can be also considered as thermodynamically

uniform. From the temperature and pressure, the properties of the vapor phase are calculated by NIST-Refprop ver. 9.0 [19]. Evaporation mass flow rate is calculated from the volume and density changes of the vapor phase, while volume change of the liquid is ignored since it is much smaller than that of the vapor phase.

In this experiment, warming-up operation is conducted before the measurement. Warming-up operation consists of 10 cycles of intake, expansion and exhaust processes. After this warming-up operation, data for 5 cycles of intake, expansion and exhaust processes are measured for data collection. Acceleration is fixed at $\alpha_{\mathrm{p}}=96 \mathrm{~mm} / \mathrm{s}^{2}$ in the warming-up operation. Figure 4 shows the example of temperature, pressure and displacement variations during warming-up and data acquisition operations. Liquid temperature $T_{\text {nozzle }}$ measured in the inlet nozzle gradually increases 
during the warming-up operation and kept at the range within $\pm 2{ }^{\circ} \mathrm{C}$ of the operating temperature during the data acquisition operation. Output work is calculated by taking the average of 5 cycles of the $P-V$ diagram. Adiabatic efficiency is also evaluated from the $P-V$ diagram.

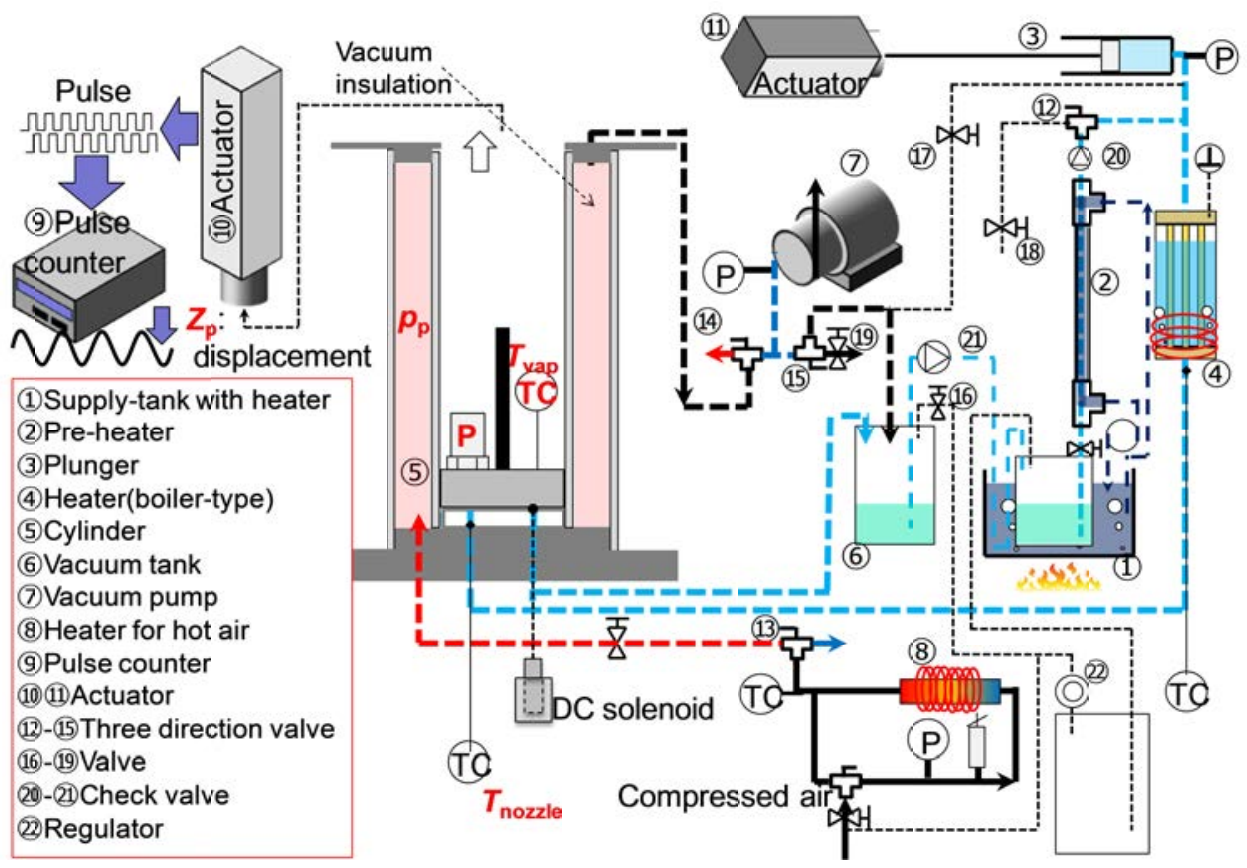

Fig. 1 Schematic of the experimental setup.

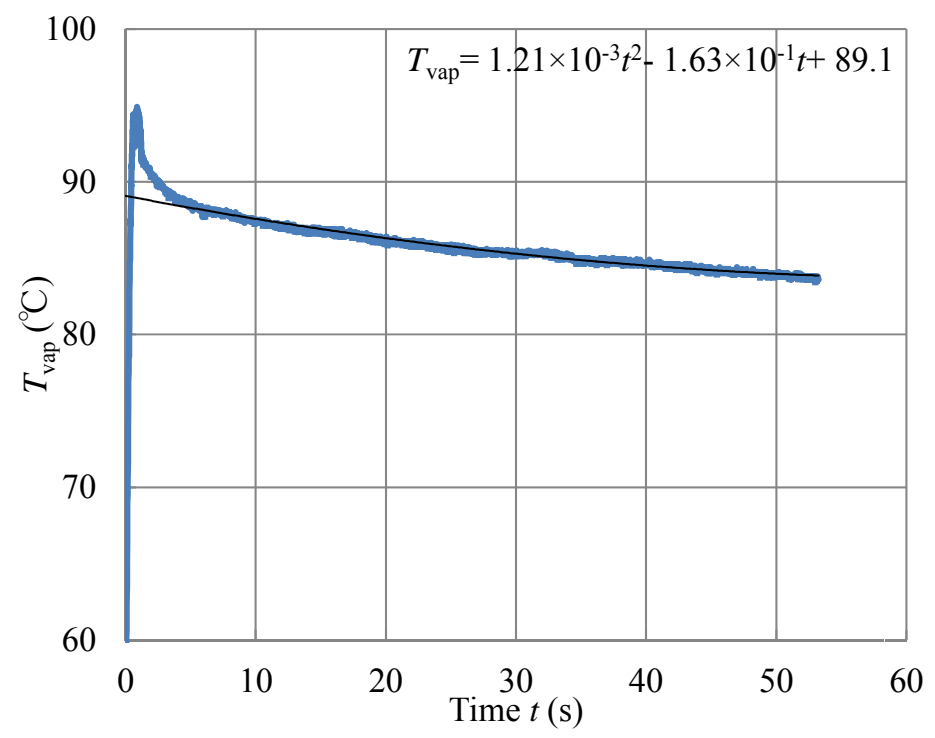

Fig. 2 Vapor temperature change for water and $T_{\text {inj }}=100{ }^{\circ} \mathrm{C}$ after injection during vacuum insulation 

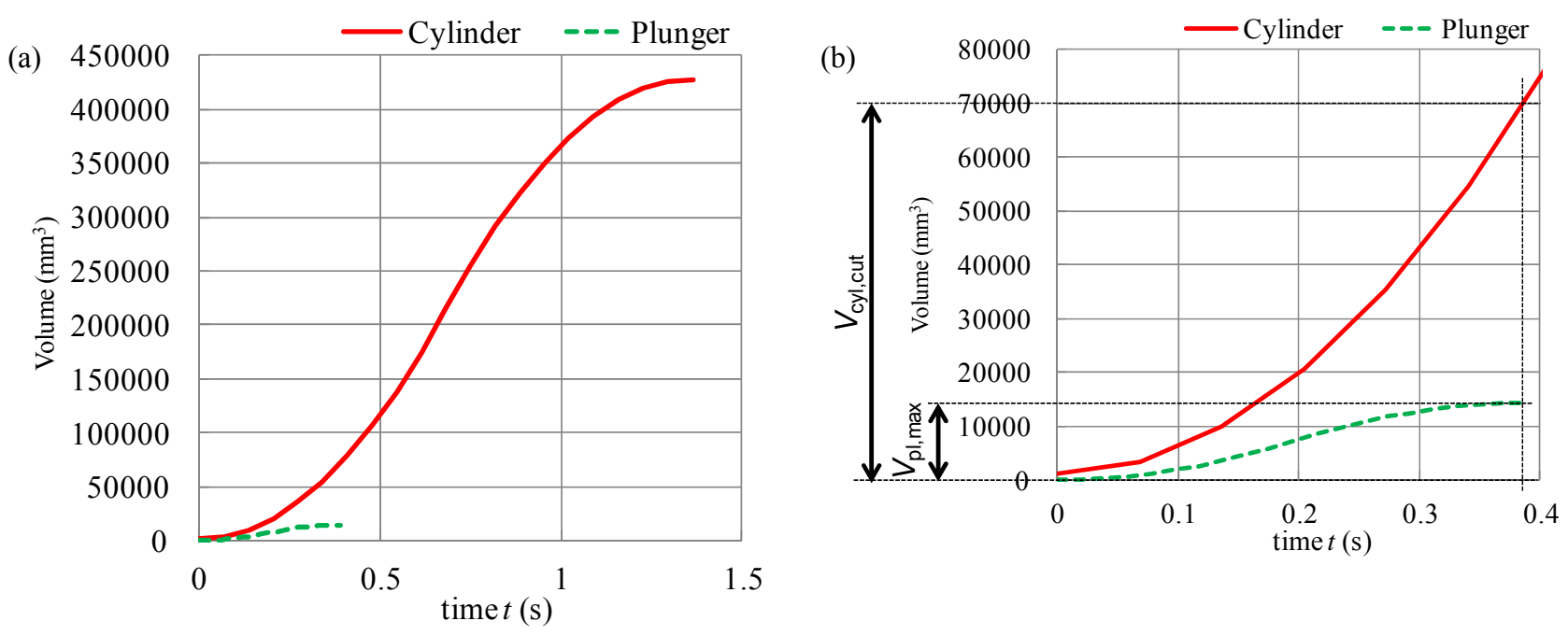

Fig. 3 Volume change of the cylinder and the plunger. (a) From top dead center to bottom dead center, (b) magnified view near the early stage of expansion.

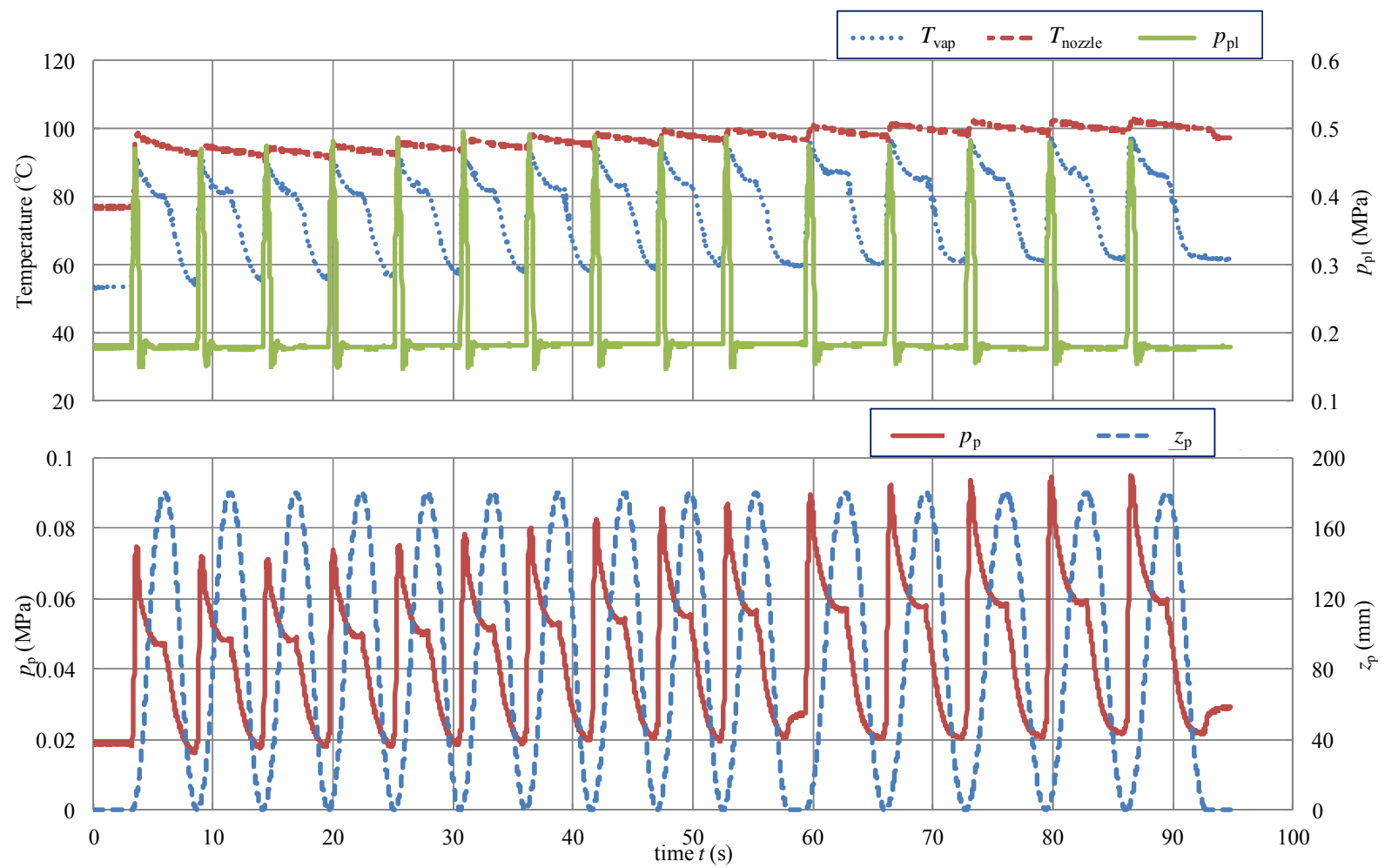

Fig. 4 Example of measured temperature, pressure and piston displacement cycles.

Table 1 Physical properties of stainless plate and cylinder.

\begin{tabular}{ccc}
\hline & $\begin{array}{c}\text { Stainless plate } \\
\text { (SUS304) }\end{array}$ & $\begin{array}{c}\text { Cylinder } \\
\text { (polycarbonate) }\end{array}$ \\
\hline$\rho\left[\mathrm{kg} / \mathrm{m}^{3}\right]$ & 9790 & 1200 \\
$c[\mathrm{~kJ} /(\mathrm{kg} \cdot \mathrm{K}))$ & 0.59 & 1.05 \\
\hline
\end{tabular}


Table 2 Experimental condition.

\begin{tabular}{c} 
Parameter \\
\hline$z_{\text {liq }}[\mathrm{mm}]$ \\
$z_{0}[\mathrm{~mm}]$ \\
$z_{\text {max }}[\mathrm{mm}]$ \\
$\alpha_{\mathrm{p}}\left[\mathrm{mm} / \mathrm{s}^{2}\right]$ \\
$V_{\mathrm{p}, \max }[\mathrm{mm} / \mathrm{s}]$ \\
$\varepsilon_{\text {cut,vol }}[\mathrm{mm} / \mathrm{s}]$ \\
$\varepsilon_{\text {exp }}[\mathrm{mm} / \mathrm{s}]$ \\
\hline$\varepsilon_{\text {cut,vol }}=\frac{V_{\text {cyl,cut }}}{V_{\text {pl,max }}}$ \\
$\varepsilon_{\text {exp }}=\frac{V_{\text {cyl,max }}}{V_{\text {pl,max }}}$
\end{tabular}

\subsection{Calibration of losses}

Figure 5 shows the schematic of work and losses. The output work is calculated from Eq. (3) using measured $P-V$ diagram. The ideal maximum output work which is the indicated work of quasi-static expansion is calculated from Eq. (4). The pressure of quasi-static expansion $p{ }_{\text {ise }}$ is calculated using initial pressure (back pressure), initial entropy and density change. When calculating the pressure of quasi-static expansion, the heat loss acquired in the calibration experiment is taken into account. First, mean density is calculated from the cylinder volume and the amount of working fluid. And then, the entropy change is calculated considering the heat loss which is calculated from the temperature change shown in Fig. 2. From the density and the entropy, the quasi-static pressure $p$ ise is obtained. Note that $p_{\text {ise }}$ is calculated by assuming that the working fluid is introduced following a movement of the piston. The adiabatic efficiency $\eta_{\mathrm{ad}}$ is defined as the ratio of the measured indicated work to that of the quasi-static expansion, as defined in Eq. (5).

In this study, heat from the liquid to the bottom plate is calculated from Eq. (6). The liquid temperature is calculated from the initial liquid temperature, evaporated mass and latent heat. The initial temperature of bottom stainless plate is assumed to be equal to the saturated temperature at the cylinder pressure $\left(p_{\mathrm{p}}\right)$ before the expansion. The bottom plate temperature and heat from liquid to the plate during expansion are calculated from Eqs. (7) and (8). The quasi-static expansion pressure $p_{\text {ise }}$ considering the heat capacity loss is calculated from the entropy, the internal density of the working fluid and the heat transferred from the liquid to the bottom plate $Q_{\text {sus }}$. Then, heat capacity loss $E_{\mathrm{hc}, \text { loss }}$ from the working fluid to the bottom plate is obtained from Eq. (9). In this calibration, we use the heat transfer coefficient $h$ obtained from the previous experiment without intake and exhaust of the working fluid [18]. Using $p_{\text {ise, }}$ heat capacity loss ratio $\zeta_{\text {hc,loss }}$ is defined as Eq. (10).

The quasi static pressure $p_{\text {ise,inj }}$ of the experimental injection condition is also obtained by using the initial entropy, density of the working fluid and the heat transferred from the liquid to the bottom plate. Note that the quasi static pressure $p_{\text {ise,inj }}$ is calculated by assuming that the fluid is introduced following the movement of piston. From $p_{\text {ise }}$ and $p_{\text {ise,inj }}$, the effect of injection loss is evaluated. The injection loss $E_{\text {inj,loss }}$ and injection loss ratio $\zeta_{\text {inj,loss }}$ are obtained from Eqs. (11) and (12). The pressure difference between $p_{\text {ise,inj }}$ and $p_{\mathrm{p}}$ is due to the non-uniformity of the liquid and vapor temperatures. Thus, the non-equilibrium loss is defined as Eqs. (13) and (14). 


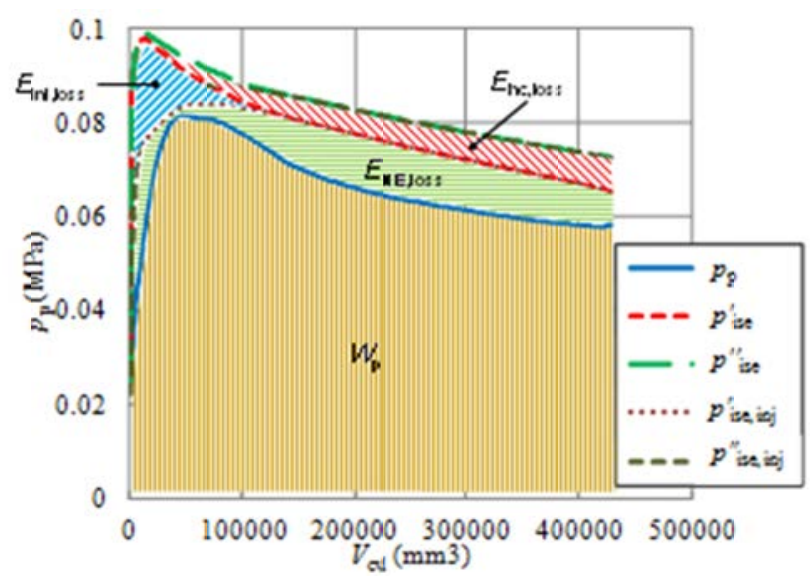

Fig. 5 Schematic of output work and losses.

$$
\begin{gathered}
W_{\text {exp }}=\int p_{\mathrm{p}} \mathrm{d} V_{\text {cyl }} \\
W^{\prime \prime}{ }_{\text {ise }}=\int p^{\prime \prime}{ }_{\text {ise }} \mathrm{d} V_{\text {cyl }} \\
\eta_{\text {ad }}=\frac{W_{\text {exp }}}{W^{\prime \prime}{ }_{\text {ise }}} \\
\frac{\mathrm{d} Q_{\text {sus }}}{\mathrm{d} t}=m_{\text {sus }} C_{\text {sus }} \frac{\mathrm{d} T_{\text {sus }}}{\mathrm{d} t}=S_{\mathrm{p}} h\left(T_{\text {sus }}-T_{\text {liq }}\right) \\
Q_{\text {sus }}=m_{\text {sus }} C_{\text {sus }}\left(T_{\text {sat }, 0}-T_{\text {sus }}\right) \\
T_{\text {sus }}=T_{\text {sat }, 0}-\frac{Q_{\text {sus }}}{m_{\text {sus }} C_{\text {sus }}} \\
E_{\mathrm{hc}, \text { loss }}=\int\left(p^{\prime \prime}{ }_{\text {ise }}-p_{\text {ise }}^{\prime}\right) \mathrm{d} V_{\text {cyl }} \\
\zeta_{\text {hc,loss }}=\frac{E_{\mathrm{hc,loss}}}{W^{\prime \prime}{ }_{\text {ise }}} \\
E_{\text {inj,loss }}=\int\left(p_{\text {ise }}^{\prime}-p^{\prime}{ }_{\text {ise, inj }}\right) \mathrm{d} V_{\text {cyl }} \\
\zeta_{\text {inj,loss }}=\frac{E_{\text {inj,loss }}}{W^{\prime \prime}{ }_{\text {ise }}} \\
E_{\mathrm{NE}, \text { loss }}=\int\left(p_{\text {ise, inj }}^{\prime}-p_{\mathrm{p}}\right) \mathrm{d} V_{\text {cyl }} \\
\zeta_{\mathrm{NE}, \text { loss }}=\frac{E_{\mathrm{NE}, \text { loss }}}{W^{\prime \prime}{ }_{\text {ise }}}
\end{gathered}
$$

\section{Experimental results}

\subsection{Visualization}

Figure 6 shows the visualization results for water at the condition of $T_{\text {inj }}=100{ }^{\circ} \mathrm{C}, \varepsilon_{\mathrm{cut}, \mathrm{vol}}=3$ and $v_{\mathrm{p}, \max }=131 \mathrm{~mm} / \mathrm{s}$. As shown in Fig. 6(a) and 6(b), the working fluid is introduced from the bottom inlet port at the beginning of the expansion process. Then, the inlet valve is closed, and boiling bubbles are generated from the edge of the bottom plate and the inlet port, as shown in Fig. 6(c) to 6(e). After the expansion process, the exhaust valve is opened. The cylinder and depressurization tank are connected and the working fluid is exhausted from the cylinder as shown in Fig. 6(f). In this process, the working fluid is flashed and the temperature of the bottom plate is estimated to be the same as the saturated temperature.

Figure 7 shows the visualization results for ethanol at the condition of $T_{\text {inj }}=80{ }^{\circ} \mathrm{C}, \varepsilon_{\mathrm{cut}, \mathrm{vol}}=3$ and $v_{\mathrm{p}, \max }=131 \mathrm{~mm} / \mathrm{s}$. 
The same phenomena as the water case are observed, while the boiling bubbles are mostly generated from the edge of the inlet port. The wettability of ethanol is better than that of water and the superheat near the inlet port is higher than the other area. This is considered to be the reason for the fact that most bubbles are generated from the edge of the inlet port.
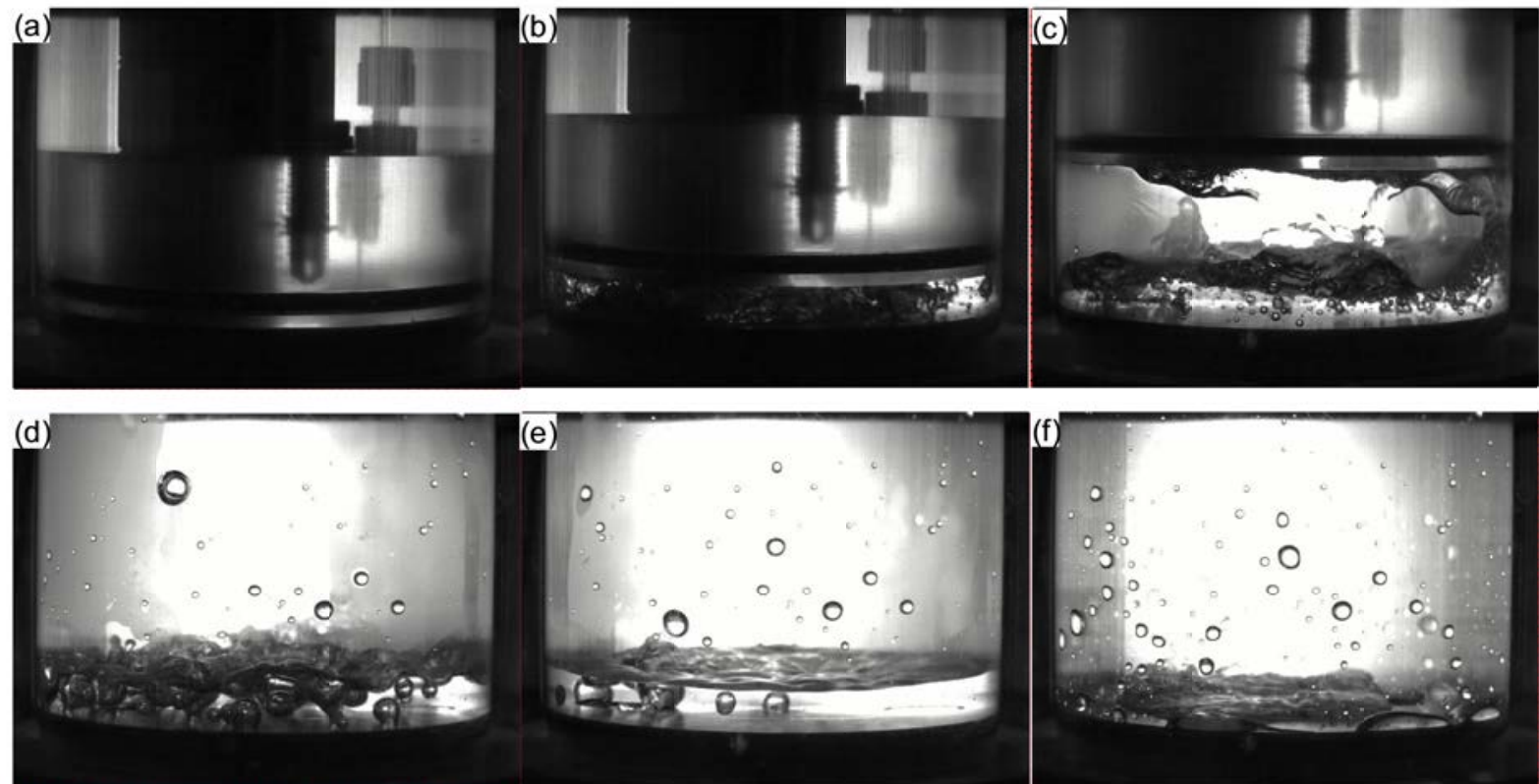

Fig. 6 Visualization for water, $T_{\text {inj }}=100{ }^{\circ} \mathrm{C}, \varepsilon_{\text {cut,vol }}=3$ and $v_{\text {p,max }}=131 \mathrm{~mm} / \mathrm{s}$. (a) $t=0.00 \mathrm{~s}$, (b) $t=0.15 \mathrm{~s}$, (c) $t=$ $0.30 \mathrm{~s}$, (d) $t=1.36 \mathrm{~s}$, (e) $t=2.72 \mathrm{~s}$ and (f) $t=4.08 \mathrm{~s}$.
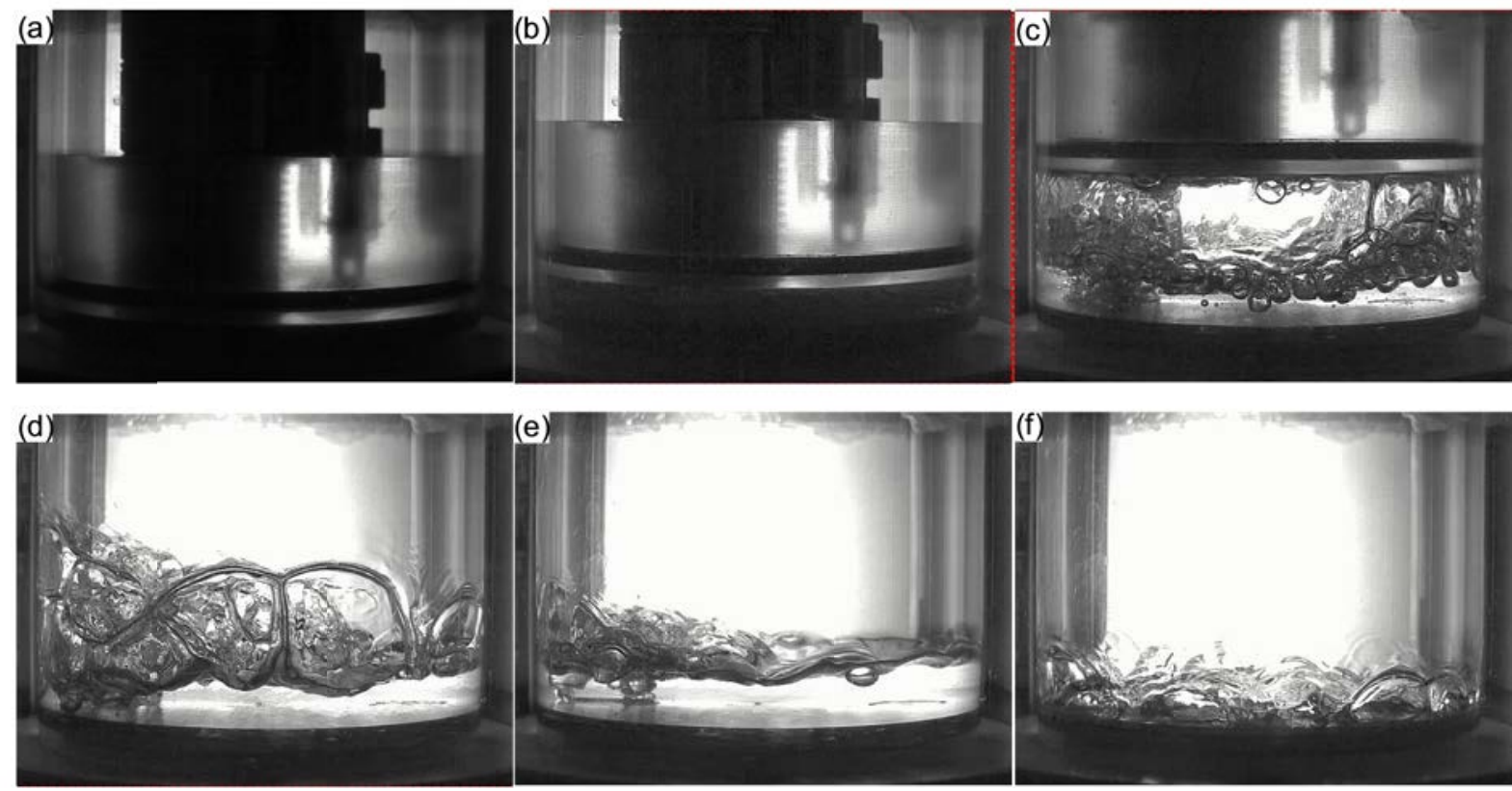

Fig. 7 Visualization for ethanol, $T_{\text {inj }}=80{ }^{\circ} \mathrm{C}, \varepsilon_{\text {cut,vol }}=3$ and $v_{\mathrm{p}, \max }=131 \mathrm{~mm} / \mathrm{s}$. (a) $t=0.00 \mathrm{~s}$, (b) $t=0.15 \mathrm{~s}$, (c) $t=$ $0.30 \mathrm{~s}$, (d) $t=1.36 \mathrm{~s}$, (e) $t=2.72 \mathrm{~s}$ and (f) $t=4.08 \mathrm{~s}$.

\subsection{Pressure and temperature changes}

Figure 8 shows the $P-V$ diagram for the water experiment, $v_{\mathrm{p}, \max }=65.4,131,263 \mathrm{~mm} / \mathrm{s}, T_{\text {inj }}=100{ }^{\circ} \mathrm{C}, \varepsilon_{\mathrm{cut}, \mathrm{vol}}=3$. 
The pressure increases immediately due to the introduction of hot working fluid. Then, pressure decreases gradually due to the two-phase adiabatic expansion. The pressure is higher for faster piston speed, which is due to the reduction of heat capacity loss from the working fluid to the cold bottom plate. Figure 9 shows the degree of superheat for the same condition, which is defined as the difference between bulk liquid and saturation temperatures. When the piston speed is increased, the superheat becomes large due to the high inner pressure as shown in Fig. 8. Figure 10 shows the evaporation mass flow rate and Fig. 11 shows the evaporated gas velocity at the interface. As can be seen from the figure, the gas normal velocity is almost proportional to the piston velocity.

Figure 12 shows the $P-V$ diagram for water experiment for $T_{\text {inj }}=100{ }^{\circ} \mathrm{C}$ and $v_{\mathrm{p}, \max }=186 \mathrm{~mm} / \mathrm{s}$ with different cut-off volume ratios from $\varepsilon_{\text {cut,vol }}=3$ to 30 . When the cut-off volume ratio is small, the introduction of hot working fluid is completed at the beginning of the expansion process. Thus, the pressure increases immediately, and then decreases by the following two-phase expansion. When the cut-off volume ratio becomes large, the hot working fluid is introduced gradually during the expansion process, so the increase of the inner pressure becomes moderate. The maximum pressure during the expansion process decreases with the increase of the cut-off volume ratio.

When the cut-off volume ratio is very small, cylinder volume is nearly unchanged during the introduction process, because the piston remains close at the top dead center. Thus, high pressure liquid is introduced into the low pressure cylinder at in a very short time. It can be considered that no heat and no work are extracted from this system. Therefore, this phenomenon is considered as isenthalpic. As the cut-off volume ratio becomes larger, i.e. as the period of introduction process becomes longer, adiabatic efficiency is reduced because of the longer isenthalpic process. 


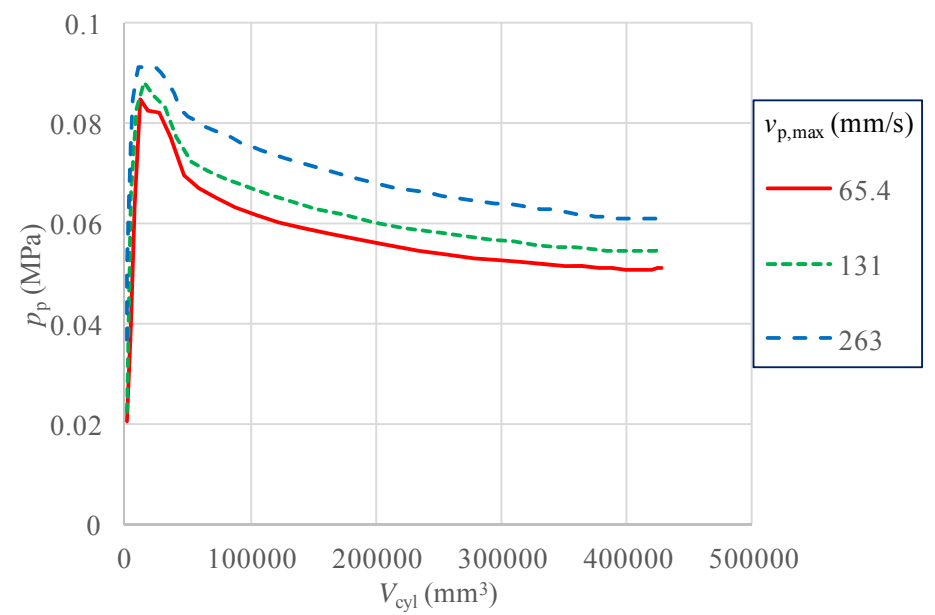

Fig. $8 P-V$ diagram for water, $T_{\text {inj }}=100{ }^{\circ} \mathrm{C}, \varepsilon_{\mathrm{cut}, \mathrm{vol}}=3$ and $v_{\mathrm{p}, \max }=$ $65.4,131,263 \mathrm{~mm} / \mathrm{s}$.

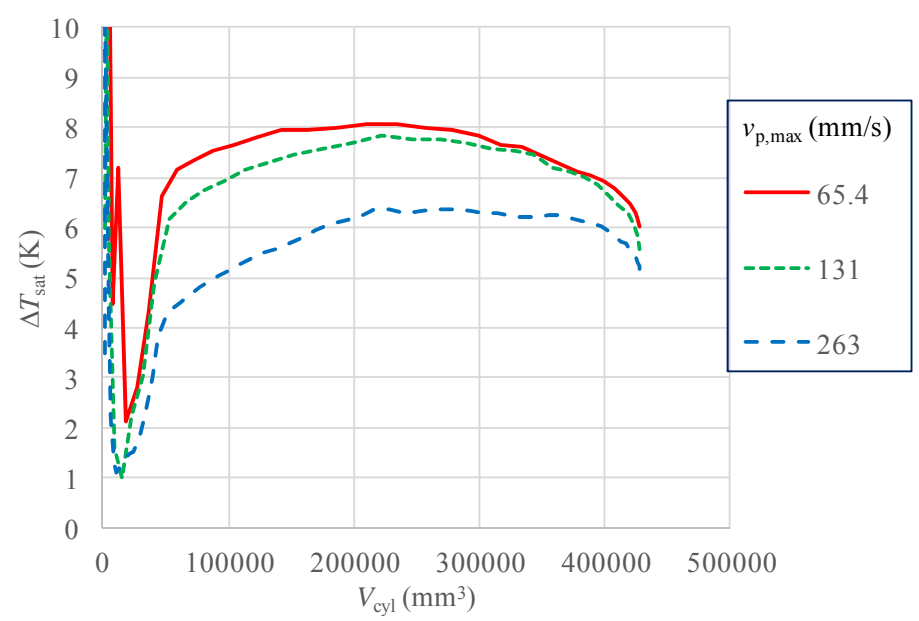

Fig. 9 Degree of superheat for water, $T_{\mathrm{inj}}=100{ }^{\circ} \mathrm{C}, \varepsilon_{\mathrm{cut}, \mathrm{vol}}=3$ and $v_{\mathrm{p}, \max }=65.4,131,263 \mathrm{~mm} / \mathrm{s}$.

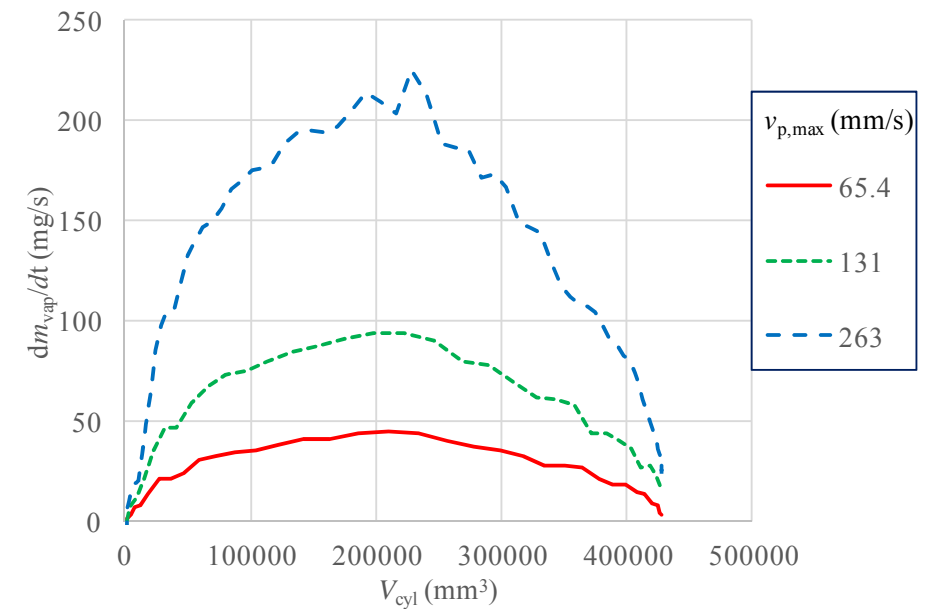

Fig. 10 Evaporation rate for water, $T_{\text {inj }}=100{ }^{\circ} \mathrm{C}, \varepsilon_{\text {cut,vol }}=3$ and $v_{\mathrm{p}, \max }$ $=65.4,131,263 \mathrm{~mm} / \mathrm{s}$. 


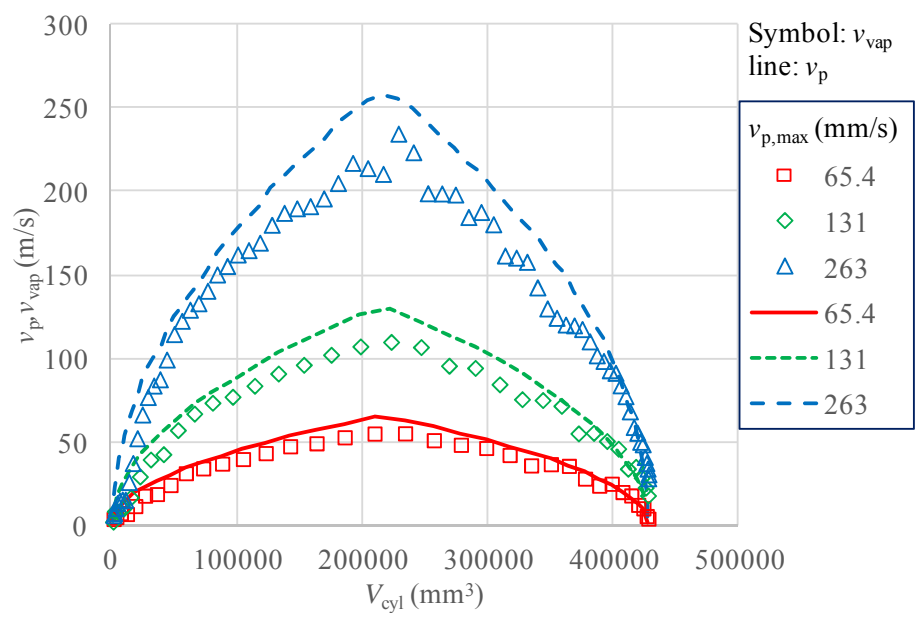

Fig. 11 Piston velocity and evaporated gas velocity at the interface for water, $T_{\mathrm{inj}}=100{ }^{\circ} \mathrm{C}, \varepsilon_{\text {cut, }, \text { ol }}=3$ and $v_{\mathrm{p}, \max }=65.4,131,263 \mathrm{~mm} / \mathrm{s}$.

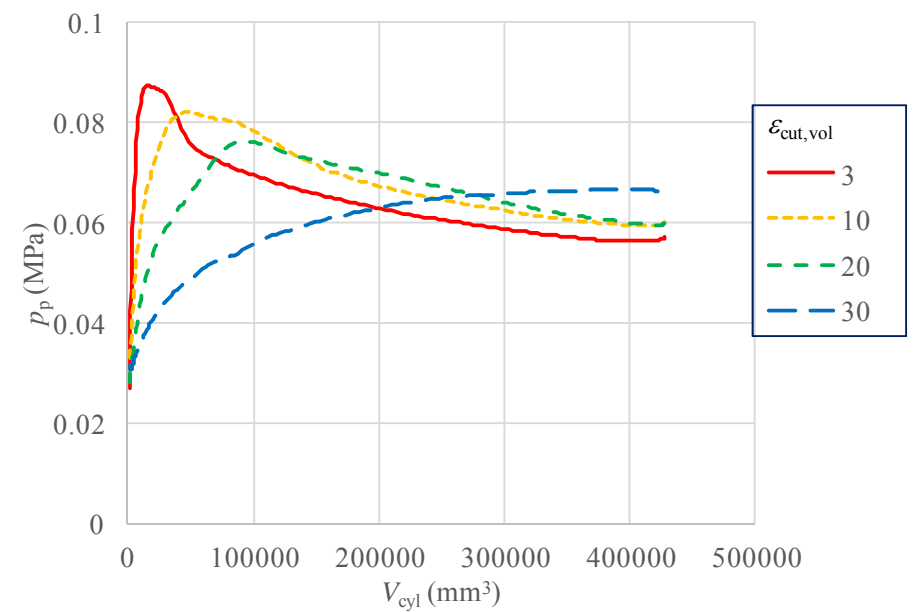

Fig. $12 P-V$ diagram for water, $T_{\text {inj }}=100{ }^{\circ} \mathrm{C}, v_{\mathrm{p}, \max }=186 \mathrm{~mm} / \mathrm{s}$ and

$$
\varepsilon_{\mathrm{cut}, \mathrm{vol}}=3-30 .
$$

\subsection{Efficiency and losses}

Figures 13 and 14 show the adiabatic efficiencies and losses for water and ethanol. Measured indicated adiabatic efficiency of water is about $86 \%$ at maximum piston velocity of $v_{\mathrm{p}, \max }=380 \mathrm{~mm} / \mathrm{s}$, while that of ethanol is about $82 \%$ for the same condition. The wettability of water is better than that of ethanol, and number of observed boiling bubbles in water are larger than that in ethanol, as can be seen from Figs. 6 and 7. Generation of large number of boiling bubbles results in enhanced mixing of the working fluid. Therefore, it is considered that the adiabatic efficiency of water is larger than that of ethanol due to the enhanced bubble generation which comes from good wettability. When the piston velocity is low, the heat capacity loss is dominant. On the other hand, heat capacity loss decreases and non-equilibrium loss becomes dominant with the increase of piston velocity. The adiabatic efficiency increases because of the reduction of heat capacity loss. It is seen that the effect of heat capacity loss becomes negligible when the piston velocity is increased.

Figure 15 shows the adiabatic efficiencies and losses for water with different cut-off volume ratios. The adiabatic 
efficiency decreases with the increase of the cut-off volume ratio, while the injection loss increases. As shown in Fig. 12 , when the cut-off volume ratio becomes large, the hot working fluid is introduced gradually and the inner pressure remains low, which results in the increase of injection loss and the decrease of adiabatic efficiency. On the other hand, non-equilibrium loss decreases slightly with the increase of cut-off volume ratio. When the cut-off volume ratio is large, the liquid phase is agitated for longer time, and this agitation effect should be the cause of non-equilibrium loss deduction at large cut-off volume ratios. From this result, it is concluded that the injection of the working fluid should be completed at the early stage of the expansion process. 


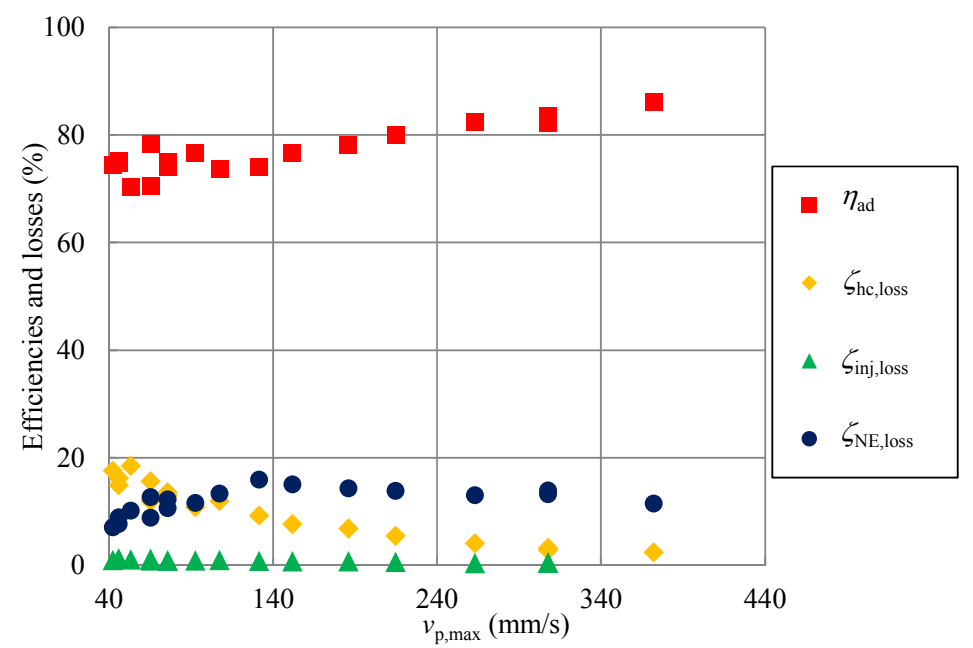

Fig. 13 Efficiency and losses against piston velocity for water, $T_{\text {inj }}=$ $100{ }^{\circ} \mathrm{C}, \varepsilon_{\text {cut }, \text { vol }}=3$.

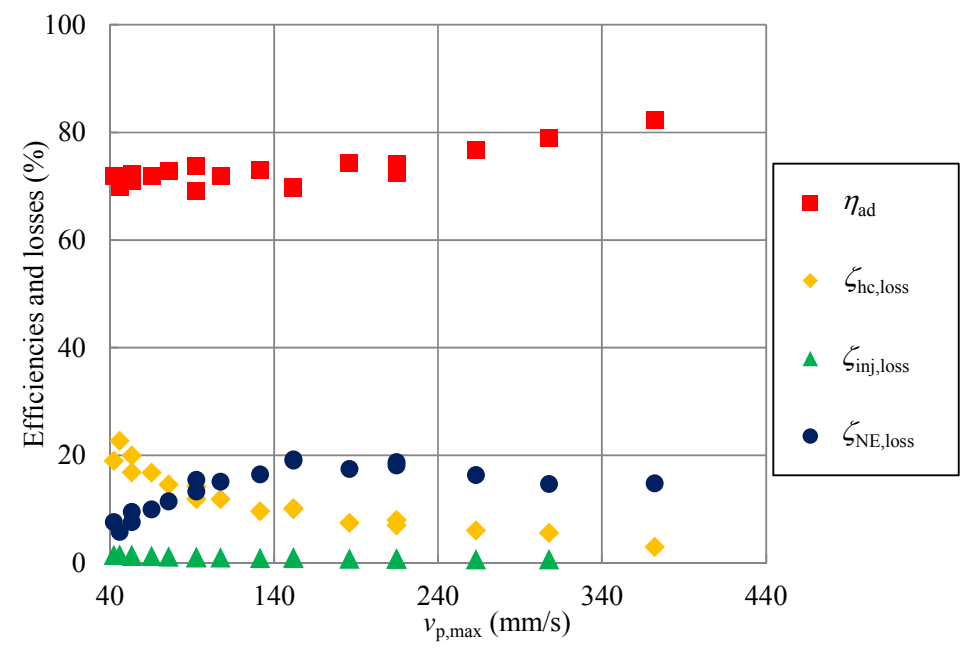

Fig. 14 Efficiency and losses against piston velocity for ethanol, $T_{\text {inj }}$ $=80{ }^{\circ} \mathrm{C}, \varepsilon_{\mathrm{cut}, \mathrm{vol}}=3$.

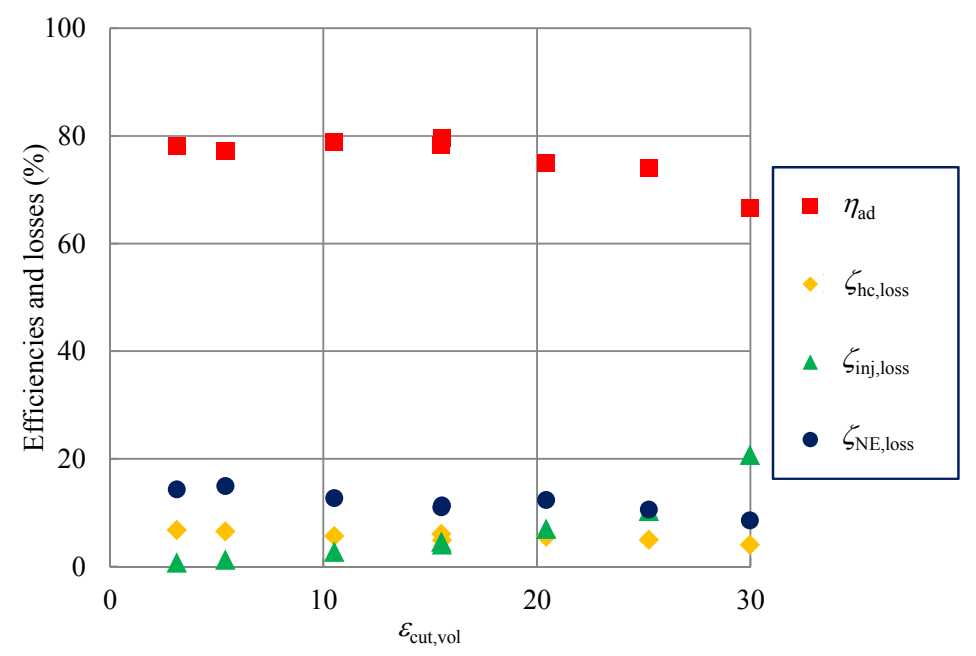

Fig. 15 Efficiency and losses for water against cut off volume ration, $T_{\mathrm{inj}}=100{ }^{\circ} \mathrm{C}, v_{\mathrm{p}, \max }=186 \mathrm{~mm} / \mathrm{s}$. 


\section{Conclusions}

Two-phase adiabatic expansion experiments in a reciprocating cylinder using water and ethanol are conducted, and indicated work and adiabatic efficiency are measured. From the results, following conclusions are obtained.

(a) Measured indicated adiabatic efficiency of water is about $86 \%$ at maximum piston velocity of $v_{\mathrm{p}, \max }=380 \mathrm{~mm} / \mathrm{s}$, while that of ethanol is about $82 \%$ for the same condition.

(b) When the piston velocity is low, the heat capacity loss is dominant, while the non-equilibrium loss becomes dominant at high piston velocity. However, non-equilibrium loss takes a maximum and decreases as piston speed is further increased.

(c) The adiabatic efficiency increases with the piston velocity, because the reduction of heat capacity loss exceeds the increase of non-equilibrium loss. The adiabatic efficiency decreases as the cut-off volume ratio is increased due to the increase of injection loss. To enhance adiabatic efficiency, injection of working fluid should be completed at the early stage of the expansion process.

\section{Acknowledgements}

This work has been partly supported by the Japan Science and Technology Agency (JST). The authors gratefully acknowledge them for the financial support.

\section{References}

1. J. Fischer, Comparison of trilateral cycles and organic Rankine cycles, Energy 36 (2011), pp. 6208 - 6219.

2. H. Kanno \& N. Shikazono ,Thermodynamic Simulations of Rankine, Trilateral and Supercritical Cycles for Hot Water and Exhaust Gas Heat Recovery, Mechanical Engineering Journal, 1 (5), p. TEP0046 (2014).

3. C. Zamfirescu \& I. Dincer, Thermodynamic analysis of a novel ammonia-water trilateral Rankine cycle, Thermochimica Acta 477 (2008), pp. 7 - 15.

4. T. Ho, S. S. Mao \& R. Greif, Comparison of the Organic Flash Cycle (OFC) to other advanced vapor cycles for intermediate and high temperature waste heat reclamation and solar thermal energy, Energy 42 (2012), pp. 213 223.

5. N. A. Lai \& J. Fischer, Efficiencies of power flash cycles, Energy 44 (2012), pp. 1017 - 1027.

6. I.K. Smith, Development of the trilateral flash cycle system. 1. Fundamental considerations, Journal of Power and Energy 207 (1993), pp. 179-194.

7. I.K. Smith \& R.P.M. Dasilva, Development of the trilateral flash cycle system. 2. Increasing power output with working fluids mixtures, Journal of Power and Energy 208 (1994), pp. 135-144.

8. I.K. Smith, N. Stosic \& C.A. Aldis, Development of the trilateral flash cycle system. 3. The design of high-efficiency two-phase screw ex panders, Journal of Power and Energy 210 (1996), pp. 75-93.

9. H.Ohman \& P. Lundqvist, Experimental investigation of a Lysholm Turbine operating with superheated, saturated and 2 - phase inlet conditions, Applied Thermal Engineering 50 (2013), pp. 1211 - 1218.

10. M. Oreijah, A. Date \& A. Akbarzadaha, Comparison between Rankine Cycle and Trilateral Cycle in Binary System for Power Generation, Applied Mechanics and Materials 464 (2014), pp 151-155.

11. M. Steffen, M. Lofffler \& K. Schaber, Efficiency of a new Triangle Cycle with flash evaporation in a piston engine, Energy, Vol.57 (2013), pp. 295-307. 
12. J. Bao \& L. Zhao, A review of working fluid and expander selections for organic Rankine cycle, Renewable and sustainable Energy Reviews 24 (2013), pp. 325 - 342.

13. S. Clemente, D. Micheli, M. Reini \& R. Taccani, Energy efficiency analysis of Organic Rankine cycles with scroll expanders for cogenerative applications, Applied Energy 97 (2012), pp. $792-801$.

14. J. Yan, D. Zhang, D. Chong, G. Wang, L. Li, Experimental study on static/circulatory flash evaporation, International Journal of Heat and Mass Transfer 53 (2010), pp 5528-5535.

15. D. Zhang, D. Chong, J. Yan, Y. Zhang, Study on steam-carrying effect in static flash evaporation, International Journal of Heat and Mass Transfer 55 (2012), pp 4487-4497.

16. D. Saury, S. Harmand, M. Siroux, Flash evaporation from a water pool:Influence of the liquid height and of the depressurization rate, International Journal of Thermal Sciences 44 (2005), pp 953-965.

17. S. Mutair, Y. Ikegami, Experimental study on flash evaporation from superheated water jets: Influencing factors and formulation of correlation, International Journal of Heat and Mass Transfer 52 (2009), pp 5643-5651.

18. H. Kanno and N. Shikazono, Experimental and Modeling Study on Adiabatic Two-phase Expansion in a Cylinder, International Journal of Heat and Mass Transfer, 86 (2015), pp. 755-763.

19. E.W. Lemmon, M.L. Huber \& M.O. McLinden, NIST standard reference database 23: reference fluid thermodynamic and transport properties e REFPROP version 9.0. Gaithersburg: National Institute of Standards and Technology, Standard Reference Data Program; 2010. 